\title{
Circulatory Compromise in a Great Horned Owl (Bubo virginianus)
}

\author{
LORI R. ARENT \\ THE RAPTOR CENTER \\ University of Minnesota, College of Veterinary Medicine \\ St. PAUl, Minnesota
}

\begin{abstract}
The temporary loss of circulation to an appendage can be deadly for a wild raptor. If restricted blood flow is suspected, an aggressive treatment protocol should be started immediately to improve circulation and minimize damage to soft tissues and bone. The treatment protocol used by The Raptor Center, College of Veterinary Medicine, at the University of Minnesota includes warm compresses applied to the affected area as well as drug therapy to dilate blood vessels, antibiotics to prevent possible infection, and anti-inflammatories. The prognosis of these cases is guarded and the outcome often difficult to predict. Therefore, even in cases with severe circulatory compromise to an area, treatment is recommended.
\end{abstract}

Keywords: raptors, circulatory compromise

\section{INTRODUCTION}

What do kite string, fishing line, frostbite, power lines, and outer wing fractures have in common? They can all lead to severe circulatory compromise of soft tissues and bone in wild raptors. Every year The Raptor Center, College of Veterinary Medicine, at the University of Minnesota (TRC) receives raptor patients suffering from injuries resulting in a loss of circulation to extremities. Without an adequate blood supply, death of soft tissues can occur within an hour, often beginning in deeper layers and gradually moving to the surface. Loss of circulation to an area may be indicated by a cool temperature to the touch; change in skin color, such as from yellow to salmon due to frostbite to the feet; or extensive bruising/swelling with edema, a build up of fluid under the skin. Prognosis of this type of injury is guarded, as probability of recovery depends on the length of time circulation has been restricted, extent of circulatory compromise, and how quickly treatment can be initiated. The following is an account of medical care provided to a great

Lori Arent is Clinic Manager at The Raptor Center. She has an MS in Veterinary Biology from the University of $\mathrm{MN}$ and is a master falconer. horned owl (Bubo virginianus) suffering from a circulatory insult to its left wing.

Great horned owl 08-051 was navigating its home territory in Moorhead, Minnesota on 16 February 2008. It landed in a tree decorated with holiday lights and when it tried to leave, became entangled. The string of lights surrounded the bird's left wing, rendering it flightless. The bird landed on the ground, where the homeowner discovered it the following morning. The local police department was called, apprehended the owl, and removed the string of lights (Figure 1). However, the bird was still unable to fly and reportedly just hopped on the ground. TRC was called, and with the assistance of the volunteer transport crew, the bird was driven to the Center that day.

\section{DiAgNosis}

Upon admission, the bird was bright, alert, and responsive. In the crate, a significant left wing droop was visible. The owl's plumage was fairly good with the exception of a few frayed primary flight feathers on its left wing. Based on plumage characteristics and weight (1530 g [3.3 lbs]), the bird was determined to be a second year female and the keel score was estimated to be four out of five (a score of 1 represents emaciation, a score of 5 represents obesity; a healthy score for a wild raptor falls within the 3.5-4 range). The birds left wing was swollen from the distal humerus to the wing tip, was red in color, and cool to the touch. Two tiny skin openings on the ventral surface of the metacarpus ( $2 \mathrm{~mm}[0.08 \mathrm{in}])$ were also present. The condition of its eyes, ears, mouth, right wing, legs, feet, vent, and back were all within normal limits, and no external parasites were observed. The owl's body temperature was $39.4^{\circ} \mathrm{C}\left(102.9^{\circ} \mathrm{F}\right)$. In addition, the following standard diagnostic tests were performed with the results indicated: 


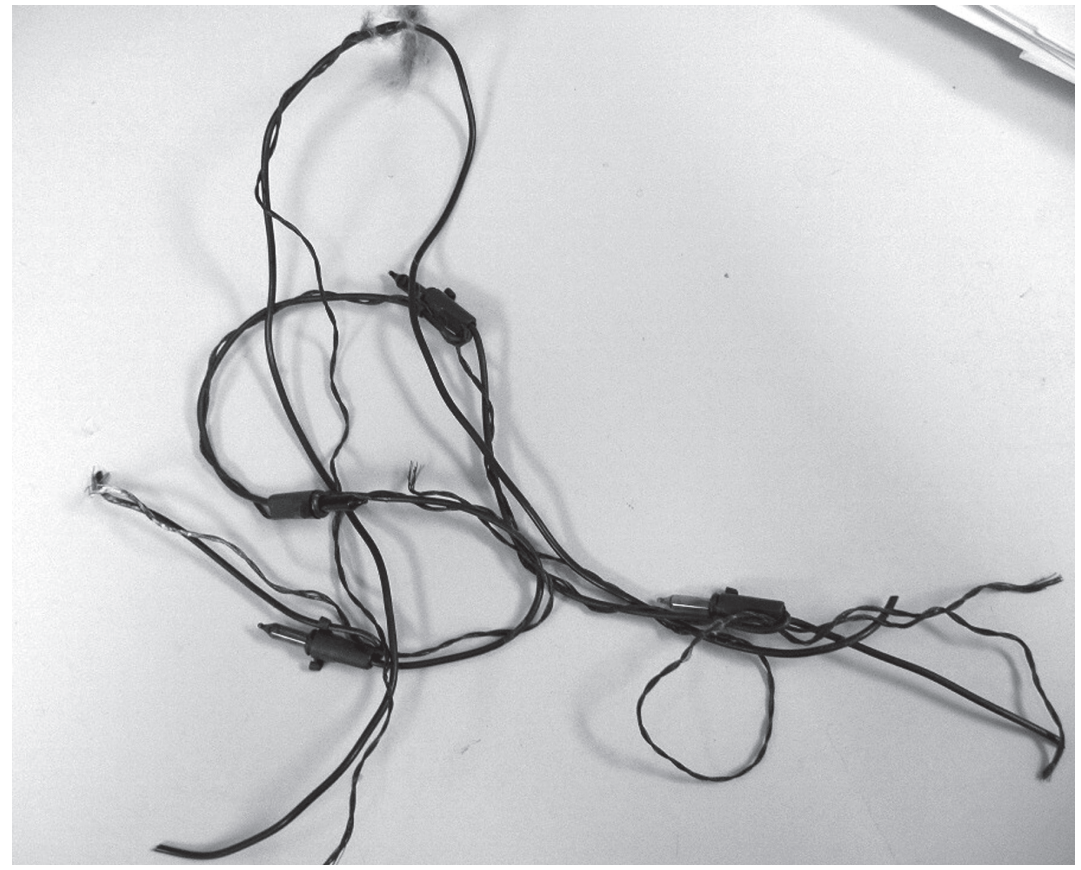

Figure 1. String of holiday lights entangled around the left wing of great horned owl 08-051.

- Radiographs: Whole-body ventrodorsal and lateral views-normal except for evidence of soft tissue swelling to the left wing.

- Complete blood count (CBC): Packed cell volume (PCV) of 50 percent total solids (TS) of $4.0 \mathrm{~g} / \mathrm{dL}$, white blood cell count estimate (WBC) of 33,000 cells $/ \mathrm{mcL}$. The differential was 76 percent heterophils, 9 percent lymphocytes, and 15 percent monocytes, with no eosinophils or basophils reported. No blood parasites were seen. Red blood cell morphology was normal and 1 to 2 percent of the heterophils were toxic.

- Fecal: Direct smear and float-positive for coccidia.

Based on this information, the preliminary diagnosis was soft tissue trauma to the left wing with circulatory compromise due either to constriction by the string of holiday lights or frostbite.

\section{TREATMENT}

Supportive care was given and treatment for the affected wing was initiated. At the time of admission, the owl was given 40cc lactated Ringers solution (LRS) with $10 \mathrm{mg} / \mathrm{kg}$ vitamin B complex subcutaneously into the inguinal area $(20 \mathrm{cc}$ on each side). Fluids were administered twice daily every twelve hours (q12hr) for two subsequent days $(50 \mathrm{cc} / \mathrm{kg} /$ day $)$ until the bird was self-feeding. The TRCs treatment protocol for circulatory compromise was begun and included the following:

- Isoxsuprine (a peripheral vaso-

dilator that helps to increase circulation) (Vasodilan, MeadJohnson

Pharmaceuticals, a Bristol-Myers, Squibb Company, Prinston, NJ): $10 \mathrm{mg} / \mathrm{kg}$ orally q24hr (once daily).

- Amoxicillin/clavulinic acid (Clavamox ${ }^{\circledR}$, Pfizer Animal Health, New York, NY) (a broad spectrum antibiotic to treat possible infection): $50 \mathrm{mg} / \mathrm{kg}$ orally q $12 \mathrm{hr}$.

- Meloxicam (Metacam ${ }^{\circledR}$, Boehringer Ingelheim Vetmedica $\mathrm{GmbH}$, Ingelheim, Germany) (a non-steroidal anti-inflammatory to treat inflammation and reduce discomfort): $0.2 \mathrm{mg} / \mathrm{kg}$ orally q24hr.

- Dimethylsulfoxide (DMSO- a solvent that reduces inflammation and promotes circulation): applied topically to affected area q24hr.

- Warm moist compresses to affected wing for 15 minutes q12hr.

- Wing immobilized with a body wrap to provide support and prevent feather damage.

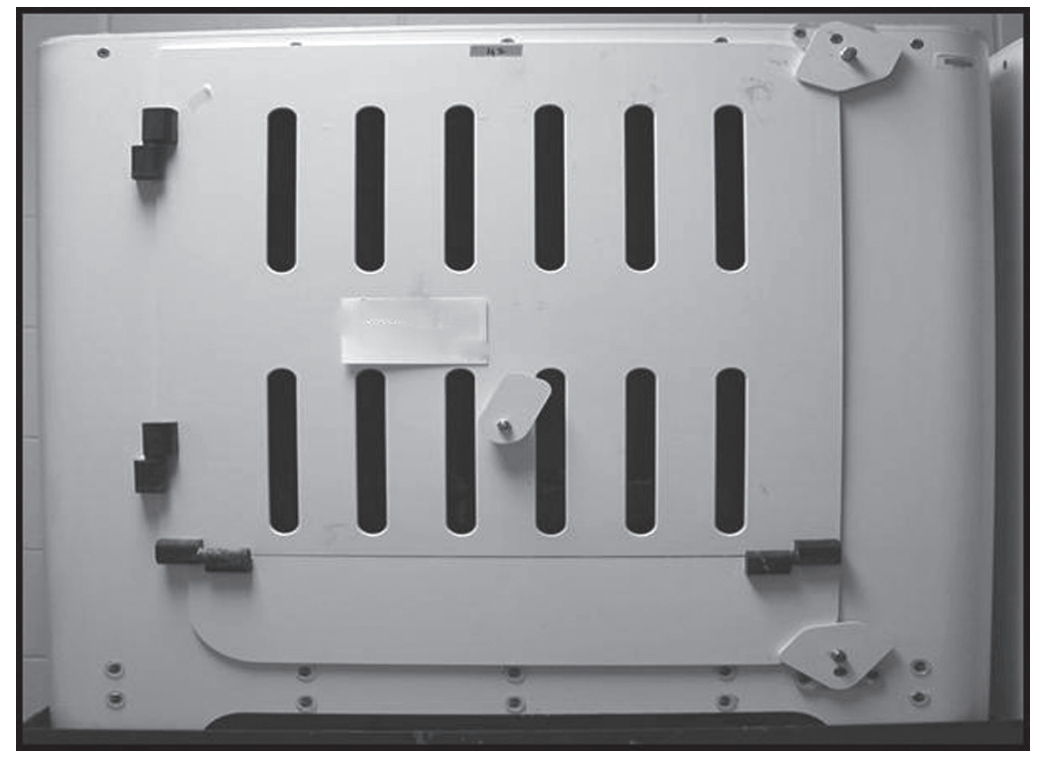

Figure 2. Convalescent cage.

The owl was housed in a convalescent cage $(76 \mathrm{~cm}$ x $86 \mathrm{~cm} \times 71 \mathrm{~cm}$ [30 in x 34 in x $28 \mathrm{in}$ ]) and offered two mice (Figure 2). After not eating for two days the owl was hand fed. On day three it began eating on its own and was maintained on $100 \mathrm{~g}$ meat (rat, mice, chicken) daily for the duration of recovery. 
Little change was noted on day two. However, on day three, the distal wing tip became edematous but was warm to the touch (Figure 3). Fluid remained under the skin for three days before beginning to resolve. Subsequently the skin's reddish color changed to purple, indicative of bruising. Warm compresses and medical grade DMSO (dimethyl sulfoxide) were applied to the skin for the first three days until the wing was warm to the touch. When administering DMSO topically, caution must be exercised. First, for the avian patient, prolonged treatment can cause skin sloughing: thus DMSO was discontinued after three days (Patrick Redig, DVM, The Raptor Center, St. Paul, MN, personal communication). Second, for the caregiver administering DMSO, contact with skin or respiratory membranes should be avoided as some people have adverse reactions to exposure, such as severe eye and respiratory irritations (Dimethyl sulfoxide Material Data Safety Sheet 2006). The body wrap was removed on day six, at which time the owl exhibited only a slight wing droop at rest. The isoxuprene, Clavamox ${ }^{\circledR}$, and Metacam ${ }^{\circledR}$ were continued for nine days until the bruising and swelling were greatly reduced (Figure 4).

Treatment for coccidia was initiated on day four, after the bird was eating well on its own. The drug currently used to treat coccidia is sulfadimethoxine (Albon ${ }^{\circledR}$, Pfizer, New York, NY) dosed at $25 \mathrm{mg} / \mathrm{kg}$ q24hr for three consecutive days (Carpenter 2001).

\section{EVALUATION}

Eleven days following admission, a repeat $\mathrm{CBC}$ was taken to assess the bird's general health. The bird had a PCV of 35 percent, TS of $3.2 \mathrm{~g} / \mathrm{dl}$, and WBC estimate was 19,250 cells/mcL. The differential cell count was 63 percent heterophils, 22 percent lymphocytes, 8 percent monocytes, 7 percent eosinophils,

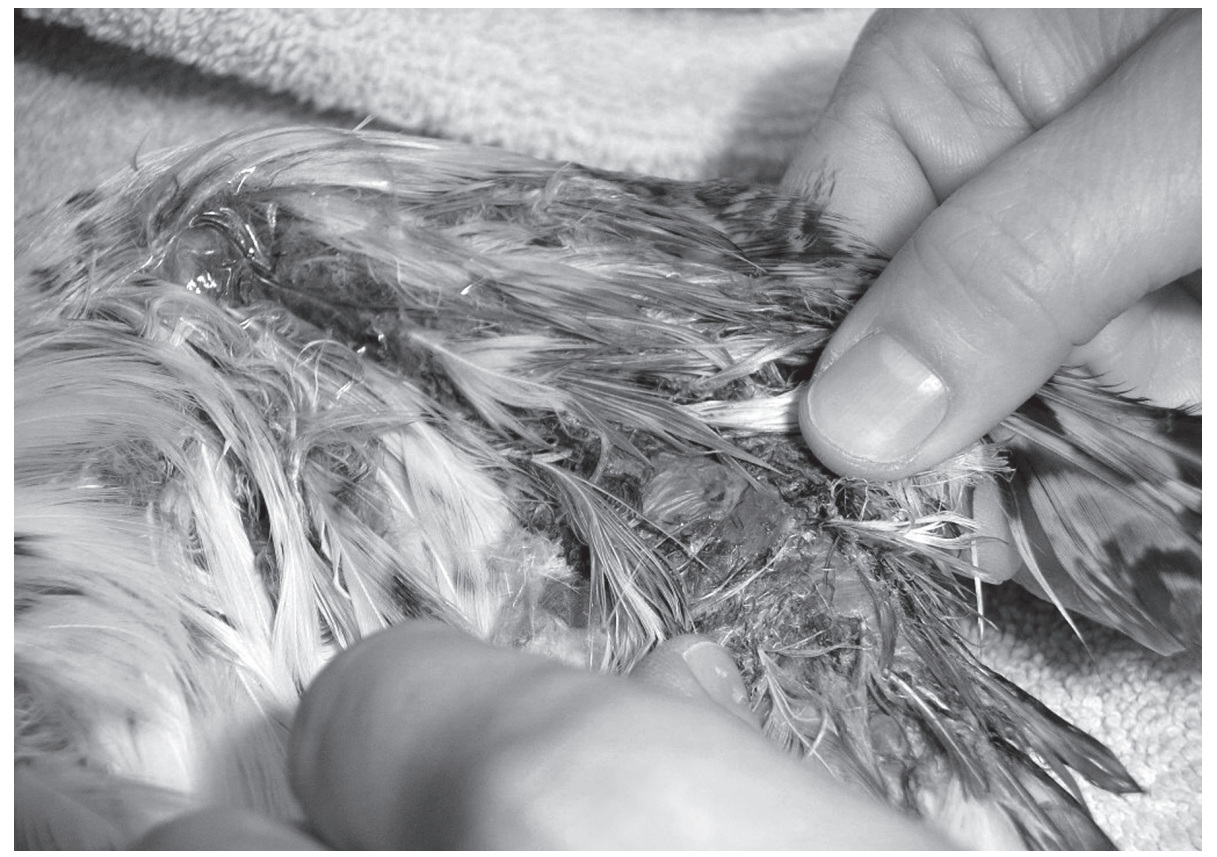

Figure 4. Edema and bruising resolving on left wing on day eight. and 0 percent basophils. The morphology of red blood cells was normal and the heterophils were no longer toxic.

The next step was to assess the bird's flight ability. On 29 February 2008, almost two weeks postadmission, the bird was placed in a $16.8 \mathrm{~m} \times 2.4 \mathrm{~m} \mathrm{x}$ $2.7 \mathrm{~m}(55 \mathrm{ft} \times 8 \mathrm{ft} \times 9 \mathrm{ft})$ indoor flight hall containing perches on either end. The bird was able to fly the distance but indicated a definite weakness in the left wing. Additional cage rest was recommended. 
On 9 March 2008, a recheck radiograph and fecal were taken. The radiograph was within normal limits and the fecal was negative. The bird was test flown again in the flight hall. The left wing was stronger and the bird flew with greater ease to the far perch. The owl was moved to an outdoor enclosure $(5.5 \mathrm{~m} \times 3.6$ $\mathrm{m} \times 2.7 \mathrm{~m}$ [18 ft $\times 12 \mathrm{ft} \times 9 \mathrm{ft}]$ ) and housed with five other great horned owls undergoing rehabilitation.

\section{PRE-ReleAse CoNditioning}

The owl was placed on an exercise program utilizing creance flight and flown twice the first week and two to three times during subsequent weeks, following protocols established by Chaplin et al (1990). The bird is expected to make a full recovery and be returned to the location of capture in Moorhead, MN.

\section{SUMMARY}

If presented with a patient where circulatory compromise to an appendage is suspected, an aggressive treatment protocol should be initiated as soon as possible to improve blood flow and treat damaged tissues. Sometimes damage is so severe that despite treatment efforts, tissue and/or bone death still occurs.
However, many times this is not the case and if caught early enough and treated properly, circulation can be improved and tissue death minimized. Therefore, even if the affected appendage looks bad upon admission, it is still recommended to begin treatment and assess continually. This owl's wing seemed to deteriorate for the first few days before showing improvement. However, in a similar case of frostbite in an owl received a few weeks previously, the wing tip continued to deteriorate and approximately 10 days after admission, showed complete tissue and bone death. It is difficult to predict the outcome at the early stages following circulatory insult, thus the best action to take is to pursue treatment.

\section{LITERATURE CITED}

Carpenter, J. W., T. Mashima, and D. Rupiper. 2001. Exotic Animal Formulary. W. B. Saunders Company: Philadelphia, PA.

Chaplin, S., L. Mueller, and L. Degernes. 1990. Physiological Assessment of Rehabilitated Raptors Prior to Release. Wildlife Journal. 12(1):7-8, 17-18. Dimethyl sulfoxide Material Data Safety Sheet. 2006. Available from: <www.Gaylordchemical.com>. (N.

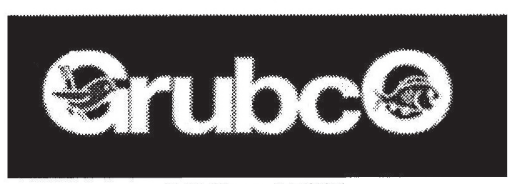

PO Box 15001

Hamilton, $\mathrm{OH} 45015$

$800-222-3563$

Known for quality \& service since 1951

As a wildlife rehabilitator, you are looking for quality live feeder insects that are high in nutritional value, have a long shelf life, and are easy to store. We offer a nutritional analysis of our products to show you exactly what you are feeding your animals. You can view the analysis and read the easy instructions on how to store our products at www.grubco.com. You can order online or call 800-222-3563. No other company provides better service and quality than Grubco. 